\title{
Clinical outcomes of a scapular-focused treatment in patients with subacromial pain syndrome: a systematic review
}

\author{
Elja A E Reijneveld, ${ }^{1}$ Suzie Noten, ${ }^{2}$ Lori A Michener, ${ }^{3}$ Ann Cools, ${ }^{4}$ Filip Struyf ${ }^{2}$
}

\begin{abstract}
- Additional material is published online only. To view please visit the journal online (http://dx.doi.org/10.1136/ bjsports-2015-095460)

'Physical Therapy Science, Program in Clinical Health Sciences, University Medical Center Utrecht, Utrecht University, Utrecht, The Netherlands

2MovAnt, Department of Rehabilitation Sciences and Physiotherapy, Faculty of Medicine and Health Sciences, University of Antwerp, Antwerp, Belgium

${ }^{3}$ Division of Biokinesiology and Physical Therapy, University of Southern California, LoS Angeles, California, USA ${ }^{4}$ Department of Rehabilitation Sciences and Physiotherapy, Faculty of Medicine and Health Sciences, Ghent University, Gent, Belgium
\end{abstract}

\section{Correspondence to}

Professor Filip Struyf, Faculty of Medicine and Health Sciences, University of Antwerp, Universiteitsplein 1, Wilrijk 2610, Belgium; Filip.struyf@ uantwerpen.be

Accepted 12 May 2016 Published Online First 1 June 2016
CrossMark

\begin{tabular}{l}
\hline To cite: Reijneveld EAE, \\
Noten S, Michener LA, \\
et al. Br J Sports Med \\
2017:51:436-441. \\
\hline
\end{tabular}

\section{ABSTRACT}

Objective To systematically review the literature on the clinical outcomes of scapular-focused treatments in participants with subacromial pain syndrome (SPS). Design Systematic literature review. Studies were appraised by two reviewers using the Physiotherapy Evidence Database (PEDro) scale, and a best-evidence synthesis was performed.

Data sources The literature search was conducted in the databases PubMed, Embase and Cinahl up to February 2015.

\section{Eligibility criteria for selecting studies}

Randomised controlled trials evaluating the clinical outcomes of a physiotherapeutic scapular-focused treatment in participants with SPS.

Results Four studies were included describing various scapular-focused interventions, including scapularfocused exercise therapy, scapular mobilisation and scapular taping. All included studies had a PEDro score of 6 or higher, indicating low risk of bias. There was moderate evidence that scapular-focused treatment compared with other physiotherapeutic treatment is effective in improving scapular muscle strength in participants with SPS. Conflicting evidence was found for improvements in pain, function and clinical measures of scapular positioning. No evidence was found for improvements in shoulder range of motion or rotator cuff muscle strength.

Conclusions There is some support for the use of scapular-focused exercise therapy in patients with SPS. Owing to the low number of studies, no firm conclusions can be drawn. Therefore, more randomised controlled trials are needed to determine the clinical outcomes of scapular-focused exercise therapy, scapular mobilisation techniques and scapular taping in patients with SPS.

\section{INTRODUCTION}

Shoulder pain is commonly reported in the general population and is a medical and socioeconomical burden in Western society. ${ }^{1}$ Many patients with shoulder pain have persistent symptoms, with $46 \%$ still reporting symptoms after 6 months. ${ }^{2}$

The subacromial pain syndrome (SPS) encompasses a large group of shoulder problems that cause pain localised around the acromion, often worsening during or subsequent to lifting of the arm. ${ }^{3}$ Optimal scapular positioning on the thorax and scapular control during shoulder movements may be important for normal shoulder function. ${ }^{4}$ Altered scapular positioning and movement patterns may be important risk factors for SPS, although evidence is conflicting. ${ }^{5-7}$
In patients with SPS, lower trapezius and serratus anterior muscle activity is decreased, whereas upper trapezius muscle activity is increased. ${ }^{8-10}$ These altered muscle activation patterns are associated with altered scapular kinematics, including reduced scapular upward rotation and posterior tilt. ${ }^{8911}$ Pectoralis minor muscle tightness and posterior glenohumeral capsular stiffness are other biomechanical factors associated with an abnormal scapular position and may be contributing risk factors for SPS. ${ }^{12-14}$ On the basis of these abnormalities in shoulder biomechanics, scapular-focused rehabilitation interventions have been recommended. ${ }^{5}$ 15-17

Scapular-focused treatment aims to restore scapular position and movement patterns, which encompass a large part of the kinetic chain of the shoulder. $^{5}$ Several systematic reviews have investigated the effectiveness of a variety of physiotherapeutic interventions for patients with SPS. ${ }^{18-21}$ However, the clinical effects of a scapular-focused treatment approach in patients with SPS are not known. ${ }^{5}{ }^{15-17}$ Therefore, the aim of this study is to systematically review the literature on the clinical outcomes of scapular-focused treatment in participants with SPS.

\section{METHODS}

This systematic review follows the guidelines outlined in the Preferred Reporting Items for Systematic Reviews and Meta-Analyses (PRISMA). ${ }^{22}$ Analytical methods and inclusion criteria were specified in advance and have not been changed post hoc.

\section{Search strategy}

The electronic databases PubMed, Embase and Cinahl were searched for eligible articles up to 23 February 2015. The following keywords were used: shoulder pain (MeSH (medical subject heading)); shoulder impingement syndrome (MeSH); shoulder bursitis $(\mathrm{MeSH})$; frozen shoulder; shoulder instability; scapula; physical therapy modalities $(\mathrm{MeSH})$; intervention; exercise; taping; manual therapy; mobilisation; motor control. The complete search strategy can be found in online supplementary appendix A.

Articles were eligible for this systematic review if: (1) study participants were patients with SPS; (2) a physiotherapeutic scapular-focused treatment was applied (including scapular-focused exercise therapy, scapular mobilisation techniques and scapular taping); (3) the study included at least one clinical outcome measure of pain, function, 
shoulder range of motion (ROM), muscle strength or clinical measures of scapular positioning; (4) the study was a randomised controlled trial (RCT) published in full text in English, Dutch or German. Studies were excluded if participants had a history of shoulder surgery, shoulder fracture or other traumatic injuries, cervical spine involvement, or neurological disorders causing muscle weakness in the shoulder.

\section{Selection of studies}

The search strategy identified 793 potentially relevant articles (figure 1). Two independent reviewers (EAER and FS) determined article eligibility for inclusion. Initially, articles were screened for eligibility on title and abstract. When titles and abstracts implied that an article was potentially eligible for inclusion, the full text article was retrieved. In addition, reference tracking was performed for all included articles.

\section{Assessment of risk of bias}

Risk of bias was assessed independently by two researchers (EAER and SN), who were blinded to each other's quality assessment. All studies were scored using the PEDro critical appraisal tool for experimental studies in physiotherapy. ${ }^{23}$ PEDro is a reliable tool ${ }^{24}$ consisting of 11 items. Item 1 is related to external validity and is not used in the scoring, as described in the PEDro guidelines. Each criterion can be answered with 'yes' or 'no'. 'Yes' was rated with 1 point, 'no' with 0 points. The possible maximum score is 10 points. Studies with a total PEDro score of at least 5 points were considered to have low risk of bias. Absolute agreement between the reviewers was calculated using the intraclass correlation coefficient (ICC). Disagreement between the reviewers regarding the quality score of an article was discussed until consensus was reached. If necessary, a third opinion was sought (FS). Publication bias was not assessed, given the early stage of evidence.

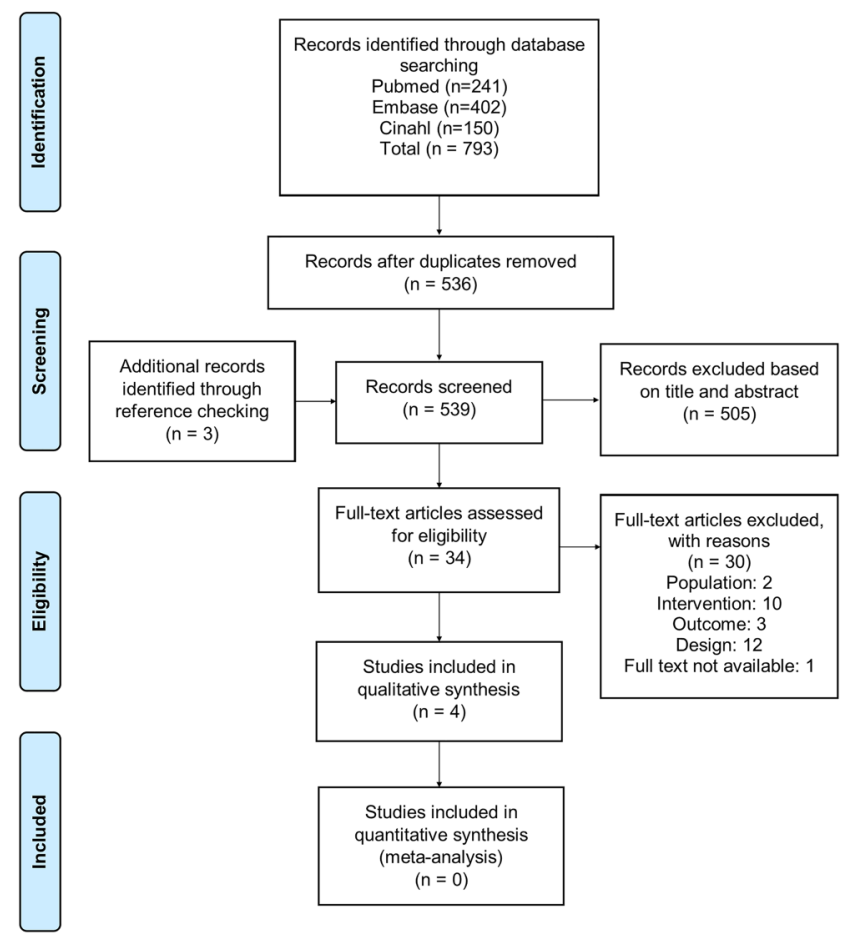

\section{Data extraction and management}

The following data were extracted from the included articles: (1) author, year and study design; (2) participant characteristics; (3) type of intervention and frequency; (4) outcome measures and follow-up; (5) main results. If data were missing or further information was required, serious attempts were made to contact the first two authors of the article to request the required information. A best-evidence synthesis was performed according to the levels of evidence for effectiveness as described in table $1 .{ }^{25} \mathrm{~A}$ meta-analysis was deemed unfeasible because of the small number of studies and heterogeneous outcome measures.

\section{RESULTS}

The process of study selection is presented in figure 1. Finally, a total of four articles were included in this review. ${ }^{26-29}$ Study characteristics of the participants, interventions, outcome measures and main results of the included studies are presented in table 2. There were three $\mathrm{RCTs}^{2628} 29$ and one randomised crossover trial. ${ }^{27}$ The sample size of the included studies ranged from 17 to 40 participants. The interventions consisted of scapular-focused exercise therapy, ${ }^{26}$ a combination of scapularfocused exercise therapy and scapular mobilisation techniques, ${ }^{29}$ and scapular taping. ${ }^{27} 28$

\section{Assessment of risk of bias}

Risk of bias scores for included studies are shown in table 3. There was absolute agreement between the two reviewers (intraclass correlation coefficient of 0.756 ). All included studies had a Pedro score of 6 or higher, indicating low risk of bias.

\section{Pain}

Pain was measured in three studies, using a visual analogue scale $\left(\right.$ VAS) ${ }^{2628} 29$ and a verbal numeric rating scale (VNRS). ${ }^{29}$ One study found significant improvements in favour of the experimental group. ${ }^{29}$ Struyf et $a l^{29}$ found a significant and clinically relevant improvement in pain during impingement screening (mean difference in VNRS between groups 3.1; $p=0.022$ ) and pain during movement (mean difference in VAS $1.5 ; \mathrm{p}=0.046$ ) after nine sessions of scapular-focused exercise therapy and scapular mobilisation. Two studies reported no significant differences in pain scores between groups after an intervention of scapular stabilisation exercises ${ }^{26}$ or scapular taping. ${ }^{28}$ In conclusion, there is conflicting evidence that a scapular-focused treatment is beneficial for reducing pain in patients with SPS.

\section{Function}

Function was measured in two studies, using the Shoulder Pain and Disability Index ${ }^{28}$ and the Shoulder Disability Questionnaire (SDQ). ${ }^{29}$ One study found significant differences between groups. ${ }^{29}$ Struyf $e t ~ a l^{29}$ reported a significant and clinically relevant difference in function between groups in favour

Table 1 Levels of evidence

\begin{tabular}{ll}
\hline Strong evidence & $\begin{array}{l}\text { Consistent (ie, when } \geq 75 \% \text { of the trials report the same } \\
\text { findings) positive (significant) findings within multiple } \\
\text { randomised clinical trials (RCTs) of good quality }\end{array}$ \\
Moderate & $\begin{array}{l}\text { Consistent positive (significant) findings within multiple RCTs } \\
\text { of low quality and/or one RCT of good quality } \\
\text { evidence }\end{array}$ \\
$\begin{array}{l}\text { Limited evidence } \\
\text { Conflicting }\end{array}$ & $\begin{array}{l}\text { Positive (significant) findings within one RCT of low quality } \\
\text { evidence }\end{array}$ \\
No evidence & $\begin{array}{l}\text { Studies reported consistent findings) } \\
\text { intervention and control groups were reported }\end{array}$ \\
\hline
\end{tabular}

Figure 1 Flow chart: search and screening of the included studies. 
Table 2 Characteristics of included studies

\begin{tabular}{|c|c|c|}
\hline $\begin{array}{l}\text { Author, year } \\
\text { and design }\end{array}$ & $\begin{array}{l}\text { Participant } \\
\text { characteristics }\end{array}$ & Interventions \\
\hline $\begin{array}{l}\text { Baskurt } \\
\text { et al, }{ }^{26} \mathrm{RCT}\end{array}$ & $\begin{array}{l}\mathrm{n}=40 ; 13 \mathrm{~m}, 27 \mathrm{f} \\
\text { Age: } \\
\text { Exercise: } 51.5 \pm 8.4 \\
\text { Control: } 51.3 \pm 11.6 \\
\text { Diagnosis: } S P S \\
\text { Drop-outs: } 0\end{array}$ & $\begin{array}{l}\text { Exercise: flexibility and strengthening exercises and } \\
\text { scapular stabilisation exercises } \\
\text { Control: flexibility and strengthening exercises } \\
\text { Flexibility exercises: anterior, posterior and inferior capsule } \\
\text { stretching, forward flexion ROM, abd ROM, IR stretching. } \\
\text { Strengthening exercises: subscap, infra, supra, anterior } \\
\text { part of deltoid and posterior part of deltoid. } \\
\text { Scapular stabilisation exercises: scapular PNF exercises, } \\
\text { scapular clock exercise, standing weight shift, double arm } \\
\text { balancing, scapular depression, wall push up, wall slide } \\
\text { exercises } \\
\text { Frequency: each exercise } 3 \text { sets, 3/week for } 6 \text { weeks }\end{array}$ \\
\hline
\end{tabular}

Outcome measures

Pain (VAS)

Shoulder ROM: flexion, abd, IR $\left(90^{\circ}\right)$, ER $\left(90^{\circ}\right)$ (goniometer) Muscle strength: Supra, Subscap, Infra, LT, MT, UT, SA (HHD in kg) Scapular motion: LSST in neutral position, $45^{\circ}$ abd, $90^{\circ}$ abd $(\mathrm{cm})$ Follow-up: baseline and 6 weeks

Frequency: each exercise 3 sets, 3/week for 6 weeks

$\begin{array}{ll}\text { Hsu et al, }{ }^{27} & \mathrm{n}=17 ; \\ \text { cross-over } & \text { Age: } 23 \pm 2.8 \\ \text { design } & \text { Diagnosis: SPS } \\ & \text { Drop-outs: } 0\end{array}$

$\begin{array}{ll}\text { Miller et al, }{ }^{28} & \mathrm{n}=22 ; 10 \mathrm{~m}, 12 \mathrm{f} \\ \text { pilot RCT } & \text { Age (range): } \\ & \text { Exercise: } 62 \text { (51-67) } \\ & \text { Control: } 54.5 \\ & \text { (45.5-62.5) } \\ & \text { Diagnosis: SPS } \\ & \text { Drop-outs: } 5\end{array}$

$\begin{array}{ll}\text { Struyf et al, }{ }^{29} & \mathrm{n}=22 ; 10 \mathrm{~m}, 12 \mathrm{f} \\ \text { RCT } & \text { Age: } \\ & \text { Exercise: } 46.2 \pm 13.5 \\ & \text { Control: } 45.5 \pm 15.1 \\ & \text { Diagnosis: SPS } \\ & \text { Drop-outs: } 2\end{array}$

\section{Participants received elastic taping and placebo taping} over the lower trapezius muscle in randomised order. Elastic tape: Y-shaped Kinesio tape, applied with minimal tension

Placebo tape: Y-shaped $3 \mathrm{M}$ Micropore tape without any stretch force

Frequency: 2 taping sessions, separated by at least 3 days.

Exercise: routine physiotherapy treatment and scapular taping

Control: routine physiotherapy treatment

Scapular taping: two straps of adhesive tape Routine physiotherapy treatment: soft tissue massage, joint mobilisation techniques and exercise (scapula and RC stabilisation and stretching).

Frequency: taping 3/week for the first 2 weeks; routine physiotherapy was received for 6 weeks.

Exercise: scapular-oriented treatment, protocol $\mathrm{A}$ Control: exercise therapy and manual therapy, protocol B Protocol A: passive manual scapular mobilisation; stretching exercises for the levator scapulae, rhomboids muscles and pectoralis minor muscle; and scapular motor control training (including training of the trapezius and SA muscles). Home exercises: stretching, the SOE and training of the trapezius and SA.

Protocol B: eccentric muscle strength training of the RC muscles (flexion, extension, IR, ER), passive glenohumeral mobilisation, friction massage therapy \& ultrasound therapy in the subacromial region. Home exercises: eccentric muscle strength training of the RC. Frequency: 9 sessions of $30 \mathrm{~min}, 1-3 /$ week.
Muscle strength: LT (HHD in Ib) Scapular motion: upward rotation and posterior tilt during humeral elevation Follow-up: before and immediately after taping application

Pain during flexion and abd (VAS)

Pain and function (SPADI)

Shoulder ROM: flexion and abd (inclinometer)

Follow-up: baseline, 2 and 6 weeks

Pain at rest and during movement (VAS)

Pain during impingement screening (VNRS)

Function (SDQ)

Muscle strength: elevation (HHD in $\mathrm{N}$ )

Scapular motion: acromial distance index $(\mathrm{cm})$; pectoralis muscle length index $(\mathrm{cm})$ and scapular upward rotation (inclinometer)

Follow-up: baseline, immediately after treatment ( 9 sessions) and 3 months

\section{Main results}

Strength of scapular muscles

(LT, MT, UT, SA) $(\mathrm{p}<0.05)^{*}$

Exercise: $+1.05(\mathrm{LT}) ;+1.15(\mathrm{MT})$;

+1.28 (UT); +1.40 (SA)

Control: $+0.52(\mathrm{LT}) ;+0.32(\mathrm{MT})$;

+0.44 (UT); +0.52 (SA)

LSST $(p=0.00)^{*}$

Exercise: $-0.52 \mathrm{~cm}$ (neutral position); $-0.55 \mathrm{~cm}\left(45^{\circ} \mathrm{abd}\right)$;

$-0.58 \mathrm{~cm}\left(90^{\circ} \mathrm{abd}\right)$

Control: $-0.07 \mathrm{~cm}$ (neutral

position); $-0.03 \mathrm{~cm}\left(45^{\circ} \mathrm{abd}\right)$;

$0.00 \mathrm{~cm}\left(90^{\circ} \mathrm{abd}\right)$

No differences for pain, shoulder ROM and strength of the RC muscles.

Posterior tilt $(p<0.05)^{*}$

Elastic tape: $+0.39^{\circ}$ (at $30^{\circ}$ );

$+0.44^{\circ}$ (at $60^{\circ}$ )

Placebo tape: $-0.71^{\circ}$ (at $30^{\circ}$ ); $-0.75^{\circ}$ (at $60^{\circ}$ )

No differences for LT muscle strength and scapular upward rotation.

No significant differences for pain, function and shoulder ROM.

Pain during movement $(p=0.046)^{*}$ Exercise: -2.7

Control: -1.2 Pain during the Neer test $(p=0.022)^{*}$

Exercise: -2.2

Control: +0.9

Function $(p=0.025)^{*}$

Exercise: -20.9

Control: -2.2

Effects were maintained at 3 months follow-up.

No differences for elevation muscle strength and scapular motion.

*Significant improvement in favour of the intervention group as reported by the authors.

abd, abduction; ER, external rotation; $f$, female; HHD, handheld dynamometer; Infra, infraspinatus; IR, internal rotation; lb, pound; LSST, lateral scapular slide test; LT, lower trapezius; m, male; MT, middle trapezius; PNF, proprioceptive neuromuscular facilitation; RC, rotator cuff; RCT, randomised controlled trial; ROM, range of motion; SA, serratus anterior; SDQ, Shoulder Disability Questionnaire; SOE, scapular orientation exercise; SPADI, shoulder pain and disability index; SPS, subacromial pain syndrome; Subscap, subscapularis; Supra, supraspinatus; UT, upper trapezius; VAS, visual analogue scale; VNRS, verbal numeric rating scale.

of the scapular-focused intervention group (mean difference in SDQ 18.7; $\mathrm{p}=0.025)$ which included scapular mobilisation and scapular muscle interventions of stretching and motor control exercises. Miller et $a l^{28}$ found no significant difference in function between a scapular taping group and a control group. Summarising, there is conflicting evidence that a scapular-focused treatment approach improves function in patients with SPS.

\section{Shoulder ROM}

Shoulder ROM was measured in two studies. ${ }^{26} 28$ Both studies found no significant differences between the groups. ${ }^{26} 28$ Thus, there is no evidence that a scapular-focused treatment programme is effective in improving shoulder ROM in patients with SPS.

\section{Muscle strength}

Muscle strength was measured in three studies. ${ }^{26} 2729$ One study found a significant difference in muscle strength between groups in favour of the experimental group. ${ }^{26}$ Baskurt et al found a significant increase in scapular muscle strength (mean difference $0.53 \mathrm{~kg}$ for lower trapezius strength, $0.83 \mathrm{~kg}$ for middle trapezius strength, $0.84 \mathrm{~kg}$ for upper trapezius strength and $0.88 \mathrm{~kg}$ for serratus anterior strength; $\mathrm{p}<0.05$ ) after an intervention of scapular stabilisation exercises. There was no significant difference between groups for rotator cuff strength. ${ }^{26}$ 
Table 3 Risk of bias assessment of the included studies by the PEDro score

\begin{tabular}{|c|c|c|c|c|c|c|c|c|c|c|c|}
\hline Study & $\begin{array}{l}1 . \\
\text { Random } \\
\text { allocation }\end{array}$ & $\begin{array}{l}2 . \\
\text { Concealed } \\
\text { allocation }\end{array}$ & $\begin{array}{l}3 . \\
\text { Baseline } \\
\text { comparability }\end{array}$ & $\begin{array}{l}4 . \\
\text { Blinding } \\
\text { subject }\end{array}$ & $\begin{array}{l}5 . \\
\text { Blinding } \\
\text { therapist }\end{array}$ & $\begin{array}{l}6 . \\
\text { Blinding } \\
\text { assessor }\end{array}$ & $\begin{array}{l}7 . \\
\text { Outcome } \\
\text { data }>85 \%\end{array}$ & $\begin{array}{l}8 . \\
\text { Intention } \\
\text { to treat }\end{array}$ & $\begin{array}{l}9 . \\
\text { Between- } \\
\text { group } \\
\text { results }\end{array}$ & $\begin{array}{l}10 . \\
\text { Point measures/ } \\
\text { measures of } \\
\text { variability }\end{array}$ & $\begin{array}{l}\text { PEDro } \\
\text { total } \\
\text { score }\end{array}$ \\
\hline $\begin{array}{l}\text { Başkurt } \\
\text { et } a l^{26}\end{array}$ & 1 & 0 & 1 & 0 & 0 & 0 & 1 & 1 & 1 & 1 & 6 \\
\hline $\begin{array}{l}\text { Hsu } \\
\text { et }\left.a\right|^{27}\end{array}$ & 1 & 0 & 1 & 0 & 0 & 1 & 1 & 1 & 1 & 1 & 7 \\
\hline $\begin{array}{l}\text { Miller } \\
\text { et }\left.a\right|^{28}\end{array}$ & 1 & 1 & 1 & 0 & 0 & 1 & 0 & 0 & 1 & 1 & 6 \\
\hline $\begin{array}{l}\text { Struyf } \\
\text { et }\left.a\right|^{29}\end{array}$ & 1 & 1 & 1 & 0 & 0 & 1 & 1 & 1 & 1 & 1 & 8 \\
\hline
\end{tabular}

Hsu $e t a l^{27}$ and Struyf et $a l^{29}$ also found no significant differences between groups for rotator cuff muscle strength. In conclusion, after a scapular-focused treatment, there is moderate evidence for improvement in scapular muscle strength, and no evidence for improvement in rotator cuff muscle strength in patients with SPS.

\section{Clinical measures of scapular positioning}

Scapular clinical measures were measured in three studies. $^{26} 2729$ Two studies measured scapular upward rotation, ${ }^{27} 29$ one study measured posterior tilt, ${ }^{27}$ one study used the lateral scapular slide test (LSST), ${ }^{26}$ and one study measured acromial distance and pectoralis muscle length. ${ }^{29}$ Two studies found significant differences between groups. ${ }^{26} 27$ Başkurt et $\mathrm{al}^{26}$ found significant improvements on the LSST (mean difference $0.45 \mathrm{~cm}$ at neutral position, $0.52 \mathrm{~cm}$ at $45^{\circ}$ abduction and $0.58 \mathrm{~cm}$ at $90^{\circ}$ abduction; $\mathrm{p}=0.00$ ) after an intervention of scapular stabilisation exercises. Hsu et $a l^{27}$ reported a significantly increased posterior tilt at $30^{\circ}$ and $60^{\circ}$ of arm scaption (mean difference $1.1^{\circ}$ and $1.2^{\circ} ; \mathrm{p}<0.05$ ) immediately after the application of Kinesio taping. Struyf et $a l^{29}$ did not find any significant differences between groups for scapular upward rotation, acromial distance and pectoralis muscle length. Thus, there is conflicting evidence that a scapular-focused treatment approach is effective in improving clinical measures of scapular positioning in patients with SPS.

\section{DISCUSSION}

In this review, four studies were included to assess the clinical outcomes of a scapular-focused treatment in participants with SPS. According to our best-evidence synthesis, moderate evidence was found that a scapular-focused treatment approach in comparison with other physiotherapeutic treatment approaches is beneficial in improving scapular muscle strength. Conflicting evidence was found for the effectiveness of scapular-focused treatment on pain, function and scapular clinical measures of positioning. No evidence was found for improvements in shoulder ROM or rotator cuff muscle strength after a scapularfocused treatment approach.

The inconsistencies in the evidence for the effectiveness of scapular-focused treatment on pain, function and clinical measures of scapular positioning in participants with SPS may have several reasons. First, differences in interventions between studies may have caused conflicting results. The best-evidence synthesis is based on four studies, including two that applied a scapular-focused exercise therapy programme (either combined or not with mobilisation techniques) and two studies that applied scapular taping. ${ }^{26-29}$ It can be questionable to make comparisons between heterogeneous interventions. However, in all the included studies, the aim of the intervention was to attain stability in the scapulothoracic joint. Because there were few studies available in this area, it was decided to investigate the common effect of various scapular-focused interventions in participants with SPS in this study. A second reason for conflicting findings between studies may be differences in follow-up periods between studies. Hsu et al ${ }^{27}$ investigated the effects of only one treatment session of scapular taping. One treatment session seems to be too little to objectify a real clinical change, and therefore the results of this study should be interpreted with caution. A third possible reason may be the inclusion of a pilot study which seems to be insufficiently powered to reach significance. ${ }^{28}$ In the study of Miller et al, ${ }^{28}$ no differences were found in pain, function and shoulder ROM between a scapular taping group and a control group. However, in their study, there was a short-term (at 2 weeks) trend towards reduced pain scores for the scapular taping group, which does not appear to reach significance because of the small sample size and considerable loss to follow-up.

Because of the small number of studies investigating the effectiveness of a scapular-focused treatment approach, it is difficult to make a clear recommendation for a specific scapularfocused intervention method. However, based on the results of this review, insufficient evidence was found to support the use of scapular taping. Hsu et $a l^{27}$ investigated the effectiveness of scapular taping only immediately after one treatment session, and Miller $e t a l^{28}$ did not find significant results after scapular taping because of a high drop-out rate. There are some indications that a scapular-focused exercise therapy programme (whether or not combined with scapular mobilisation techniques) has benefit in patients with SPS. In the included studies, various scapular-focused exercises were implemented in the interventions, such as scapulothoracic strengthening, stretching, stabilisation and motor control exercises. ${ }^{26} 29$ It is not known what type of exercises would be best in a scapular-focused exercise therapy programme.

Based on the findings in this systematic review, it can be questioned if improvements in scapular muscle strength and clinical measures of scapular positioning are also associated with improvements in patient-reported outcomes such as pain or function. Previous research shows that abnormalities in scapular position and movement patterns may be associated with SPS. ${ }^{8}{ }^{11}$ In the study of Baskurt et $a l,{ }^{26}$ improvements were found in scapular muscle strength and the scapular slide test. 
However, the improvements in clinical measures of scapular positioning were not supported by improvements in pain. In the study of Struyf et $a l,{ }^{29}$ improvements were found in pain and function, but no improvements were reported in clinical measures of scapular positioning. A possible explanation is that the included studies did not identify whether any scapular impairments were present in the participants. The identification of scapular impairments in individual participants might give insight into critical impairments that need to be addressed and may direct the selection of specific interventions for a scapular-focused treatment programme. Furthermore, in the included studies, scapular position and movement patterns were assessed using static or semi-dynamic measurement methods. However, currently, it is recommended that dynamic scapular tests are used for the clinical assessment of scapular movement patterns. ${ }^{5}$ In addition, impairments of scapular muscle strength and movement patterns are rarely the only factors affecting shoulder function. Therefore, other anatomical or physiological alterations that affect shoulder function also need to be investigated and addressed in the rehabilitation of patients with SPS. A scapular-focused treatment approach should be seen within the global picture of the patient's profile, where it encompasses a large part of the kinetic chain of the shoulder.

The improvements in pain and function found in some of the studies included in this review are supported by previous RCTs conducted in other populations. ${ }^{30}{ }^{31}$ Park et al ${ }^{30}$ evaluated the effects of scapular stabilisation exercises immediately after surgery in patients with SPS. They found reduced pain and improved function after treatment. In a study by Andersen et $a l,{ }^{31}$ positive effects on pain and shoulder elevation strength were reported after a scapular-focused exercise programme in patients with non-specific neck/shoulder pain. Celik et $a l^{32}$ reported improved pain scores after a scapular-focused exercise therapy programme in patients with frozen shoulder syndrome, and Surenkok et $a l^{33}$ found improved function after one session of scapular mobilisation techniques in patients with general shoulder pain. Furthermore, in multiple case series studies, positive effects on pain, function and clinical measures of scapular positioning were found after a scapular-focused exercise programme. ${ }^{34-38}$ However, in these studies no control group was included, so no conclusions can be drawn about the additional effects of a scapular-focused treatment approach in comparison with other physiotherapeutic interventions.

On the basis of the results of this review, a scapular-focused treatment seems to have no added benefit in improving rotator cuff muscle strength or shoulder ROM in patients with SPS. This is in contrast with findings of previous studies. Merolla et $a l^{34} 35$ found improved infraspinatus and supraspinatus muscle strength and increased ROM of internal rotation after a scapular-focused rehabilitation programme. However, no control group was included in these studies. Park et $a l^{30}$ reported an improved ROM of abduction after an intervention of scapular stabilisation exercises in patients with SPS, immediately after surgery. In the study of Park et al, the control group received passive treatment modalities, while in the study of Baskurt et al the control group received an exercise programme that was not scapular focused. The differences between the interventions in the control groups may have caused different results. Struyf et $a l^{29}$ and Baskurt et $a l^{26}$ reported improvements in muscle strength and shoulder ROM in both the control group and the experimental group, but no differences between groups. Therefore, rotator cuff muscle strength and shoulder ROM seem to improve after an exercise therapy programme.
However, a scapular-focused exercise programme does not seem to be more effective in improving rotator cuff muscle strength and shoulder ROM than other exercise programmes in patients with SPS.

This review is the first to systematically summarise the clinical outcomes of scapular-focused treatment in participants with shoulder disorders. However, there are some methodological limitations of this review. First, there were only a few studies conducted in the field of scapular-focused treatment in patients with SPS. The included studies had small sample sizes, did not evaluate if scapular impairments were present, and did not use appropriate measurement methods to evaluate scapular positioning and movement patterns. Second, the heterogeneity in interventions, outcome measures and follow-up periods makes it difficult to compare study results. The heterogeneity and small number of studies limited our ability to draw firm conclusions about the most effective treatment strategies focusing on scapular position and movement patterns.

For clinical practice, there are some indications that an intervention of scapular-focused exercise therapy (whether or not combined with scapular mobilisation techniques) will benefit patients with SPS. Currently, the evidence is insufficient to make a clear recommendation for the use of specific exercises in a scapular-focused intervention. No evidence was found to support the use of scapular taping. Therefore, more RCTs with adequate sample size and follow-up period are needed to determine the clinical outcomes of a scapular-focused treatment compared with other physiotherapeutic interventions. In future studies, it is recommended that scapular impairments are identified in individual participants using dynamic scapular tests. More research is needed to determine the relevance and ability of scapular impairments of muscle strength and performance to direct specific treatment interventions. Moreover, the effects of different types of scapular exercise (including stretching, strengthening, stabilisation and motor control exercises) and the effects of scapular taping and scapular mobilisation techniques should be further investigated.

\section{What are the findings?}

- Altered scapular positioning and movement patterns may be important risk factors for patients with subacromial pain syndrome (SPS).

- It is unknown whether a scapular-focused treatment approach is effective in patients with SPS.

\section{How might it impact on clinical practice in the future?}

- Scapular-focused treatment may be effective in improving scapular muscle strength in patients with subacromial pain syndrome (SPS).

- No improvement in shoulder range of motion or rotator cuff muscle strength after scapular-focused treatment in addition to other physiotherapeutic treatment.

- It is unclear what the effects of a scapular-focused treatment approach are on patient-reported outcome measures such as pain and function.

- Currently, there is no evidence to support the use of scapular taping in subjects with SPS. 


\section{SUMMARY AND CONCLUSION}

We found some support for the use of scapular-focused treatment in patients with SPS. There was moderate evidence that a scapular-focused treatment approach is effective in improving scapular muscle strength in patients with SPS. Conflicting evidence was found for improvements in pain, function and clinical measures of scapular positioning. No evidence was found for improvement in rotator cuff muscle strength or shoulder ROM. Currently, there is insufficient evidence to support a specific scapular-focused treatment approach in patients with SPS. Therefore, more research is needed to determine which scapular impairments direct the use of scapular-focused treatment and what the effectiveness is of different scapular-focused interventions in patients with SPS.

Twitter Follow Filip Struyf at @FilipStruyf

Contributors EAER devised the study, conducted the literature search, assessed studies for eligibility, conducted risk of bias assessment, and wrote and revised the manuscript. SN conducted risk of bias assessment and revised the manuscript. LAM and $A C$ critically revised the manuscript. FS was involved in the design of the study, was consulted about assessment for eligibility and risk of bias assessment, revised the manuscript, and monitored the study through to completion. All authors approved the final version of the manuscript.

Competing interests None declared.

Provenance and peer review Not commissioned; externally peer reviewed.

\section{REFERENCES}

1 Luime JJ, Koes BW, Hendriksen IJ, et al. Prevalence and incidence of shoulder pain in the general population; a systematic review. Scand I Rheumatol 2004;33:73-81.

2 Feleus A, Bierma-Zeinstra SM, Miedema HS, et al. Prognostic indicators for non-recovery of non-traumatic complaints at arm, neck and shoulder in general practice -6 months follow-up. Rheumatology (Oxford) 2007:46:169-76.

3 Diercks R, Bron C, Dorrestijn 0, et al. Guideline for diagnosis and treatment of subacromial pain syndrome: a multidisciplinary review by the Dutch Orthopaedic Association. Acta Orthop 2014;85:314-22.

4 Ludewig PM, Reynolds JF. The association of scapular kinematics and glenohumeral joint pathologies. J Orthop Sports Phys Ther 2009;39:90-104.

5 Kibler WB, Ludewig PM, McClure PW, et al. Clinical implications of scapular dyskinesis in shoulder injury: the 2013 consensus statement from the 'Scapular Summit'. Br J Sports Med 2013;47:877-85.

6 Clarsen B, Bahr R, Andersson SH, et al. Reduced glenohumeral rotation, external rotation weakness and scapular dyskinesis are risk factors for shoulder injuries among elite male handball players: a prospective cohort study. Br J Sports Med 2014;48:1327-33.

7 Myers JB, Oyama S, Hibberd EE. Scapular dysfunction in high school baseball players sustaining throwing-related upper extremity injury: a prospective study. J Shoulder Elbow Surg 2013;22:1154-9.

8 Ludewig PM, Cook TM. Alterations in shoulder kinematics and associated muscle activity in people with symptoms of shoulder impingement. Phys Ther 2000;80:276-91.

9 Lin JJ, Hanten WP, Olson SL, et al. Functional activity characteristics of individuals with shoulder dysfunctions. J Electromyogr Kinesiol 2005;15:576-86.

10 Struyf F, Cagnie B, Cools A, et al. Scapulothoracic muscle activity and recruitment timing in patients with shoulder impingement symptoms and glenohumeral instability. J Electromyogr Kinesiol 2014;24:277-84.

11 Struyf F, Nijs J, Baeyens JP, et al. Scapular positioning and movement in unimpaired shoulders, shoulder impingement syndrome, and glenohumeral instability. Scand J Med Sci Sports 2011;21:352-8.

12 Borstad JD, Ludewig PM. The effect of long versus short pectoralis minor resting length on scapular kinematics in healthy individuals. J Orthop Sports Phys Ther 2005;35:227-38.

13 Borstad JD. Resting position variables at the shoulder: evidence to support a posture-impairment association. Phys Ther 2006;86:549-57.
14 Harrington S, Meisel C, Tate A. A cross-sectional study examining shoulder pain and disability in Division I female swimmers. I Sport Rehabil 2014;23:65-75.

15 Kibler WB, Sciascia A. Current concepts: scapular dyskinesis. Br J Sports Med 2010;44:300-5.

16 Forthomme B, Crielaard JM, Croisier JL. Scapular positioning in athlete's shoulder: particularities, clinical measurements and implications. Sports Med 2008;38:369-86.

17 Voight ML, Thomson BC. The role of the scapula in the rehabilitation of shoulder injuries. J Athl Train 2000;35:364-72.

18 Green S, Buchbinder R, Hetrick S. Physiotherapy interventions for shoulder pain. Cochrane Database Syst Rev 2003;(2):CD004258.

19 Hanratty CE, McVeigh JG, Kerr DP, et al. The effectiveness of physiotherapy exercises in subacromial impingement syndrome: a systematic review and meta-analysis. Semin Arthritis Rheum 2012;42:297-316.

20 Kromer TO, Tautenhahn UG, de Bie RA, et al. Effects of physiotherapy in patients with shoulder impingement syndrome: a systematic review of the literature. J Rehabil Med 2009;41:870-80.

21 Desmeules F, Côté CH, Frémont P. Therapeutic exercise and orthopedic manual therapy for impingement syndrome: a systematic review. Clin J Sport Med 2003;13:176-82.

22 Moher D, Liberati A, Tetzlaff J, et al. Preferred reporting items for systematic reviews and meta-analyses: the PRISMA statement. BMJ 2009;339:b2535.

23 Physiotherapy Evidence Database. PEDro Scale. Secondary Physiotherapy Evidence Database. PEDro Scale. http://www.pedro.org.au/english/downloads/pedro-scale/

24 Maher CG, Sherrington C, Herbert RD, et al. Reliability of the PEDro scale for rating quality of randomized controlled trials. Phys Ther 2003;83:713-21.

25 van Tulder M, Furlan A, Bombardier C, et al. Updated method guidelines for systematic reviews in the cochrane collaboration back review group. Spine 2003;28:1290-9.

26 Başkurt Z, Başkurt F, Gelecek N, et al. The effectiveness of scapular stabilization exercise in the patients with subacromial impingement syndrome. J Back Musculoskelet Rehabil 2011:24:173-9.

27 Hsu YH, Chen WY, Lin HC, et al. The effects of taping on scapular kinematics and muscle performance in baseball players with shoulder impingement syndrome. J Electromyogr Kinesiol 2009;19:1092-9.

28 Miller P, Osmotherly P. Does scapula taping facilitate recovery for shoulder impingement symptoms? A pilot randomized controlled trial. J Man Manip Ther 2009;17:E6-13.

29 Struyf F, Nijs J, Mollekens S, et al. Scapular-focused treatment in patients with shoulder impingement syndrome: a randomized clinical trial. Clin Rheumatol 2013;32:73-85.

30 Park SI, Choi YK, Lee JH, et al. Effects of shoulder stabilization exercise on pain and functional recovery of shoulder impingement syndrome patients. J Phys Ther Sci 2013:25:1359-62.

31 Andersen $\mathrm{CH}$, Andersen LL, Zebis MK, et al. Effect of scapular function training on chronic pain in the Neck/Shoulder region: a randomized controlled trial. J Occup Rehabil 2014;24:316-24.

32 Celik D. Comparison of the outcomes of two different exercise programs on frozen shoulder. Acta Orthop Traumatol Turc 2010;44:285-92.

33 Surenkok 0, Aytar A, Baltaci G. Acute effects of scapular mobilization in shoulder dysfunction: a double-blind randomized placebo-controlled trial. J Sport Rehabil 2009;18:493-501.

34 Merolla G, De Santis E, Campi F, et al. Supraspinatus and infraspinatus weakness in overhead athletes with scapular dyskinesis: strength assessment before and after restoration of scapular musculature balance. Musculoskelet Surg 2010;94:119-25.

35 Merolla G, De Santis E, Sperling JW, et al. Infraspinatus strength assessment before and after scapular muscles rehabilitation in professional volleyball players with scapular dyskinesis. J Shoulder Elbow Surg 2010;19:1256-64.

36 Worsley P, Warner M, Mottram S, et al. Motor control retraining exercises for shoulder impingement: effects on function, muscle activation, and biomechanics in young adults. J Shoulder Elbow Surg 2013;22:e11-19.

37 De Mey K, Danneels L, Cagnie B, et al. Scapular muscle rehabilitation exercises in overhead athletes with impingement symptoms: effect of a 6-week training program on muscle recruitment and functional outcome. Am J Sports Med 2012;40:1906-15.

38 Roy JS, Moffet $\mathrm{H}$, Hébert $\mathrm{L}$, et al. Effect of motor control and strengthening exercises on shoulder function in persons with impingement syndrome: a single-subject study design. Man Ther 2009;14:180-8. 

treatment in patients with subacromial pain syndrome: a systematic review

Elja A E Reijneveld, Suzie Noten, Lori A Michener, Ann Cools and Filip Struyf

Br J Sports Med 2017 51: 436-441 originally published online June 1, 2016

doi: 10.1136/bjsports-2015-095460

Updated information and services can be found at:

http://bjsm.bmj.com/content/51/5/436

\author{
These include: \\ References This article cites 36 articles, 8 of which you can access for free at: \\ http://bjsm.bmj.com/content/51/5/436\#BIBL \\ $\begin{gathered}\text { Email alerting } \\ \text { Receive free email alerts when new articles cite this article. Sign up in the } \\ \text { service }\end{gathered}$
box at the top right corner of the online article. \\ service \\ Topic \\ Articles on similar topics can be found in the following collections \\ Collections \\ BJSM Reviews with MCQs (210) \\ Physiotherapy (188) \\ Physiotherapy (245)
}

\title{
Notes
}

To request permissions go to:

http://group.bmj.com/group/rights-licensing/permissions

To order reprints go to:

http://journals.bmj.com/cgi/reprintform

To subscribe to BMJ go to:

http://group.bmj.com/subscribe/ 